POLLACK PERIODICA

An International Journal for Engineering and Information Sciences

DOI: $10.1556 / 606.2017 .12 .3 .8$

Vol. 12, No. 3, pp. 85-98 (2017)

www.akademiai.com

\title{
EFFECT OF AIR ENTRAINING ADMIXTURE ON THE PROPERTIES OF SELF-COMPACTING CONCRETE INCORPORATING SUPPLEMENTARY CEMENTITIOUS MATERIALS
}

\author{
${ }^{1}$ Abdulkader EL MIR, ${ }^{2}$ Salem G. NEHME \\ Department of Construction Materials and Technologies, Faculty of Civil Engineering \\ Budapest University of Technology and Economics, Müegyetem rkp. 3., H-1111 Budapest \\ Hungary, e-mail: ${ }^{1}$ abdelkader.elmir@hotmail.com, ${ }^{2}$ sgnehme@yahoo.com
}

Received 10 December 2016; accepted 24 April 2017

\begin{abstract}
Self-compacting concrete has gained a wide range of applications as a result of its unique properties, which can offer high strength and durable type of concrete with the proper selection of the raw materials. The purpose of this study was to show the effect of the use of high dosage of air entraining admixture on the properties of self-compacting concrete. An experimental investigation on the frost-salt scaling resistance of conventional and air entraining selfcompacting concrete incorporating slag-blended cement and supplementary cementitious materials was carried out. Further fresh and hardened properties tests including slump flow, V-funnel, compressive strength, splitting tensile strength, air void characteristics and water absorption tests were performed to obtain an objective evaluation between air and non-air entrained self-compacting concrete mixtures. Air void characteristics were evaluated through the automated image analysis procedure to enrich this investigation. Results indicate the following: the air entraining admixture highly decreased the compressive strength up to $52 \%$ and the metakaolin was the governing supplementary cementitious material concerning the scaling resistance and water absorption in comparison with the silica fume.
\end{abstract}

Keywords: Self-compacting concrete, Air voids, Frost-salt scaling, Supplementary cementitious materials

\section{Introduction}

Self-Compacting Concrete (SCC) was development to improve the durability properties of concrete and to tackle the casting difficulties in challenging geometries. However, in order to reach the self-compacting ability, SCC rheological properties demand adequate deformability and viscosity of the paste phase [1]. Additionally, SCC 
differs from normally vibrated concrete in higher cement and super-plasticizer content, thus higher cost is needed for SCC production [2]. SCC can achieve high strength characteristics through the high volume and enhanced quality of paste, low water to binder ratio, optimized particle packing density and self-compacting ability. Therefore, the obtained dense matrix also provides durability properties for a remarkable service life design [3].

Today, the evolution and development of sustainability impose the necessity of reducing the dosage of ordinary Portland cement in concrete production. Supplementary Cementitious Materials (SCM) provide the key issue for cement replacement. These materials are generated from silica dominated (e.g. silica fume, perlite powder, quartz powder), alumino-silicates (e.g. activated clays, metakaolins) or ternary composition $\mathrm{SiO}_{2}-\mathrm{Al}_{2} \mathrm{O}_{3}-\mathrm{CaO}$ (e.g. slags and fly ashes) [4]. Due to their chemical composition, degree of crystallinity and fineness (Blaine), SCMs provide an enhancement effect on the hardened state of concrete by reacting with the $\mathrm{Ca}(\mathrm{OH})_{2}$ formed during the hydration process of Portland cement and thereby additional calcium silicate hydrate is formed [4], [5]-[9].

Concrete is subjected to several exposure conditions that highly affect its design and properties. The damage resulted from the freezing and thawing contributes to the concrete repair costs in cold climate countries. This phenomenon is described by the freezing of water inside the capillary pore structure causing the volume expansion by $9 \%$. This can result in internal tensile stresses, which may lead to a local failure of the concrete. Moreover, in the presence of deicing salts, the outer layers in contact with sodium chloride are more strongly affected by frost causing the removal of the small chips or flakes from the material. Hence, air entraining admixture is introduced to the concrete in order to ensure proper resistance against freezing and thawing. An artificial air-void system is created in cement paste to allow the uptake extension volume of the freezing water without internal damage. Standards recommend some limitation regarding the air void parameters. For instance, the American Concrete Institute (ACI) restricts the value of the spacing factor to $0.2 \mathrm{~mm}$ [10]. The European Standards do not provide specific guidelines to the air void characteristics (Table I).

For example, some High Range Water Reducing Admixtures (HRWRA) of the new generation could cause excessive air-entraining in SCC mixture. Also the concrete workability has a huge impact on the pore structure especially capillary pores located in the interfacial transition zone [11].

Previous studies have shown the effect of air entraining admixtures on the response of SCC. Since SCC is characterized by its flowing ability and viscosity, provided by special admixtures, air bubbles can move more freely in highly fluid concrete, thereby coalesced or ruptured bubbles have higher probability of occurring in SCC [3], [11], [12]. However, in SCC mixtures with a higher viscosity, air bubbles are protected against rupturing or coalescence by so called 'the cushion effect' [12]. Moreover, Struble et al. pointed out that in pastes with no HRWRA, the yield stress increased and the viscosity decreased with increasing the air content. These effects are explained by two competing mechanisms: the formation of bubble bridges, which increase the yield stress, and the fluid action of bubbles, which increases the plastic viscosity [13]. Therefore, admixtures have a significant effect on the response of air entraining admixture on the concrete paste at the fresh state. The present article shows the effect of 
air entraining admixtures, along with or without the use of SCMs on the hardened properties of SCC.

Table I

Air content requirements in concrete [14]

\begin{tabular}{|c|c|c|c|c|c|}
\hline \multirow{3}{*}{ Standard EN 206-1 } & & XF1 & XF2 & $\mathrm{XF} 3$ & XF4 \\
\hline & $\begin{array}{l}\text { Minimum air content of the fresh } \\
\text { mixture }(\%)\end{array}$ & - & 4 & 4 & 4 \\
\hline & $\begin{array}{l}\text { Minimum air content of the fresh } \\
\text { mixture }(\%)\end{array}$ & - & 2.5 & 2.5 & 4 \\
\hline $\begin{array}{l}\text { Austrian Standard } \\
\text { ÖNORM B 4710-1 }\end{array}$ & $\begin{array}{l}\text { Minimum air content of micro- } \\
\text { voids } \mathrm{A}_{300}(\%) \\
\text { Maximum void spacing factor }-\mathrm{L}\end{array}$ & - & 1 & 1 & 1.8 \\
\hline & $\begin{array}{l}\text { (mm) } \\
\text { Minimum air content of the fresh }\end{array}$ & - & - & - & 0.18 \\
\hline $\begin{array}{l}\text { Danish Standard } \\
\text { DS. } 2426\end{array}$ & $\begin{array}{l}\text { Minimum air content of the fresh } \\
\text { mixture }(\%)\end{array}$ & - & 4.5 & 4.5 & 4.5 \\
\hline & Minimum air A content $(\%)$ & - & 3.5 & 3.5 & 3.5 \\
\hline & Maximum spacing factor $-\mathrm{L}(\mathrm{mm})$ & - & 0.2 & 0.2 & 0.2 \\
\hline
\end{tabular}

Symbol: $L$ is the air void spacing factor; $A$ is the air content in hardened concrete; A300 is the content of micro-voids with a diagonal diameter of less than $0.3 \mathrm{~mm}$ in hardened concrete. All are cited according to EN 480-11 [15].

\section{Research objectives}

The aim of the current experimental investigation was to perform an objective comparison between Non Air Entrained (NAE) and Air Entrained (AE) SCC mixtures, combined with the independent effect of the SCMs: metakaolin or silica fume. Therefore, the addition of SCMs was examined under commonly applied laboratory tests for the hardened concrete specimens. A total of six separate SCC mixtures were placed and studied.

\section{Experiments}

\subsection{Materials}

In order to produce the required SCC mixtures, the following materials were applied: blast furnace cement CEM III/A $32.5 \mathrm{R}$, metakaolin, silica fume, limestone powder, river quartz aggregates (maximum aggregate size was $16 \mathrm{~mm}$ ) 4/8 $\mathrm{mm}(20 \%)$, $8 / 16 \mathrm{~mm}(35 \%)$, sand $0 / 4 \mathrm{~mm}(45 \%)$, tap water and sika chemical admixtures: the HRWRA 'Sika ViscoCrete 5 Neu' (Polycarboxylate type) and the air entraining admixture 'Sika Aer' (synthetic type). The cement properties were in relevant with EN 197-1 Standards [16]. Metakaolin produced by calcination of concentrated kaolin (mostly amorphous alumosilicate reacting with calcium hydroxide) and the silica fume slurry, were provided as the SCMs. Limestone powder in other words calciumcarbonate was the filling material that ensures the rheological properties of SCC along 
with the HRWRA. For more information, the aggregates particle size distribution plot is shown in Fig. 1 and the physical properties of fine materials are listed in Table II.

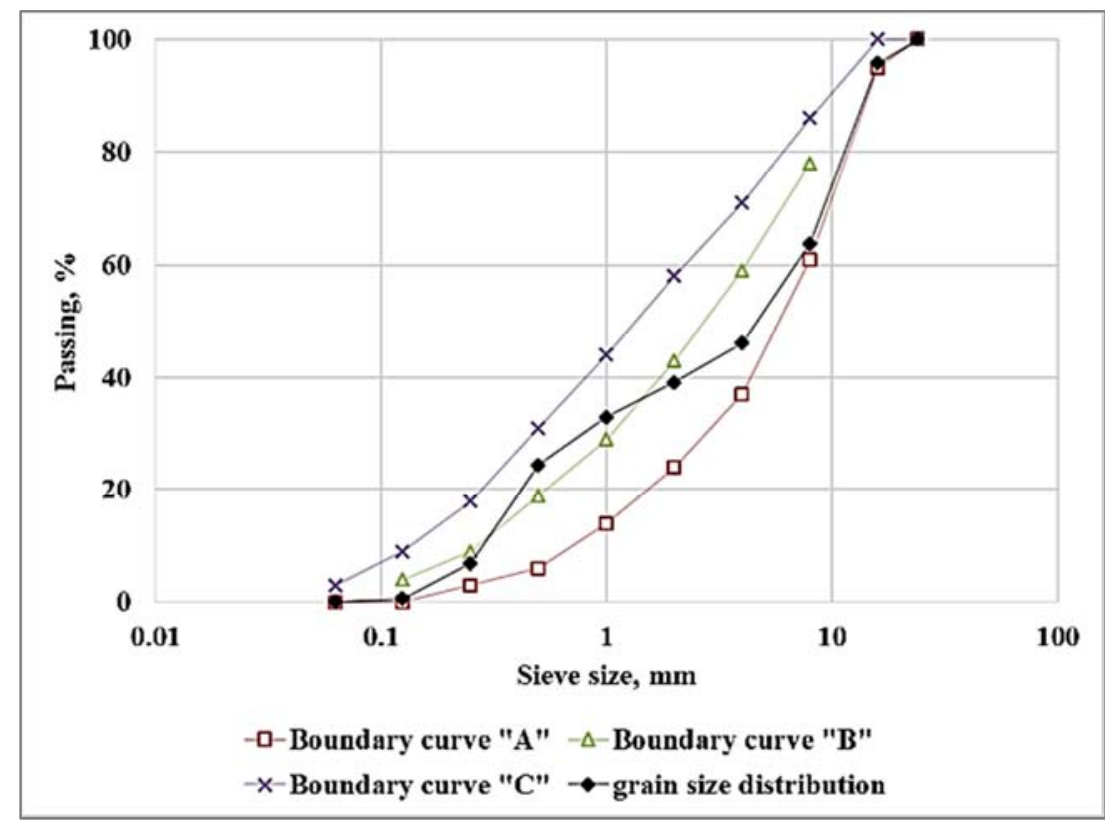

Fig. 1. Aggregate particle size distribution curve in terms with boundary conditions according to MSZ EN 12620 Standards [17]

Table II

Grading of raw materials

\begin{tabular}{|lllll|}
\hline & \multicolumn{5}{c|}{ Passing, \% } \\
\hline microns & CEM III & LP & MK & SF \\
\hline 50 & 100 & 100 & 100 & 100 \\
5 & 27 & 42.1 & 49.8 & 91 \\
0.5 & 1.9 & 2.2 & 2.3 & 30 \\
0.3 & 0.9 & 0.8 & 1.1 & 13 \\
Blaine, $\mathrm{cm}^{2} / \mathrm{g}$ & 3450 & 3470 & 15244 & 20450 \\
\hline
\end{tabular}

A total of six SCC mixtures were designed and divided into two independent series. The first series designated as the NAE series, does not hold air entraining admixture, while the second AE series provides air entraining admixture inside the mixtures. Each of these series holds a reference mixture (R), metakaolin mixture (M) and silica fume mixture (S). SCC mixtures proportions experimentally prepared, hold a constant watercement ratio $(\mathrm{w} / \mathrm{c}=0.562)$ and a slump class SF3 ranged between $750-800 \mathrm{~mm}$ [18]. Variable parameters include the use of SCMs, and air entraining admixture $(0.15 \%$ of the cement mass). For more information, the mixtures proportion of produced SCC 
mixtures is given in Table III. The mixing procedure started by mixing aggregates, limestone filler, cement and water together for one minutes. Later on, metakaolin or silica fume was added with the required amount of HRWRA to provide the necessary fresh properties for SCC production, according to European Standards [19]. The total mixing time ranged between 6-8 minutes.

\section{Table III}

Mixtures proportion

\begin{tabular}{|l|c|c|c|c|c|c|}
\hline Material & NAE & NAE & NAE & AE & AE & AE \\
$\mathrm{kg} / \mathrm{m}^{3}$ & $\mathrm{R} 1$ & $\mathrm{M} 1$ & $\mathrm{~S} 1$ & $\mathrm{R} 1$ & $\mathrm{M} 1$ & $\mathrm{~S} 1$ \\
\hline Sand 0/4 & 684 & 683 & 678 & 681 & 679 & 678 \\
Small aggregate 4/8 & 304 & 304 & 301 & 303 & 302 & 301 \\
Medium aggregate 8/16 & 532 & 531 & 527 & 530 & 528 & 527 \\
Cement & 320 & 320 & 320 & 320 & 320 & 320 \\
Limestone powder & 300 & 260 & 260 & 300 & 260 & 260 \\
Metakaolin & - & 40 & - & - & 40 & - \\
Silica fume & - & - & 40 & - & - & 40 \\
Water & 180 & 180 & 180 & 180 & 180 & 180 \\
Sika Viscocrete & 3.04 & 3.36 & 5.44 & 3.68 & 4.8 & 4.64 \\
Sika Aer & - & - & - & 0.48 & 0.48 & 0.48 \\
\hline
\end{tabular}

\subsection{Test methods}

At fresh state, the following fresh properties tests were evaluated according to EN Standards: slump flow table and V-funnel test [20], [21].

Standard cubes sized specimens $(150 \times 150 \times 150 \mathrm{~mm})$ were tested for the compressive strength by a universal closed-loop hydraulic testing machine performed based on European Standard [22] at a constant loading rate of $11.25 \mathrm{kN} / \mathrm{s}$. The ages of testing were: 7, 28, 56 and 400 days. As for the splitting tensile strength test of the concrete were in compliance with European Standards [23]. Cubes specimens 150 sized were tested at 400 days. Water absorption by complete immersion test was applied until the specimens were fully saturated so that it could be checked by no mass variation. It was followed by being oven dried for 24 hours under 100 degrees Celsius. Relative masses were recorded in order to get the water content in $\mathrm{V} \%$, which corresponds to the atmospheric water saturated condition designated by the apparent porosity. Cylindrical specimens with relative dimensions of $\varnothing 100 \times 200 \mathrm{~mm}$ were used in this evaluation and also for the body density measurement [24]. Frost scaling resistance of SCC was evaluated according to EN Standards [25] noted as 'slab test'. This protocol is based on determining the concrete resistance to repeated cycles of freezing and thawing in contact with $3 \%$ of sodium chloride solution. After $N$ number of cycles, the amount of material scaled from the tested specimen was measured. Note that results up to 56 cycles were determined. Scaling test started at the age of 28 days for concrete.

Air void distribution was analyzed using a modified point count process. Surface preparation is a very sensitive process in order to have adequate results. Hence the following procedure was carried out according to the local air void 457 suppliers. Two $150 \mathrm{~mm}$ sized cubes were transformed into three $40 \mathrm{~mm}$ concrete specimens. Each was 
grinded in both upper and bottom $150 \mathrm{~mm}$ squared surface until a smooth and totally flat surface was reached in both layers. This process was followed by special grinding and lapping steps. Basically, the slab saw products results with a fairly smooth cut; hence 125-micron disc was applied as a start of a counter clock wise lapping. The process took 2.5 minutes and a steel ruler was laid across the sample surface to ensure that the specimen is flat. Water was used for washing the sample in order to clean the voids from any debris. Afterwards the sample was rotated 90 degrees clockwise and lapped for an additional 2.5 minutes. The specimen was allowed to dry for 38 degrees Celsius in the oven followed by a coat of thinned lacquer. This cycle was repeated for $70,30,15$ and 6 micron discs respectively. Hence for more accuracy, specimens were examined under a stereo microscope for quality check [15].

\section{Results and discussions}

Table IV and Table V summarize the fresh (slump flow and V-funnel tests) and hardened (the compressive strength, splitting tensile strength, body density and water absorption by immersion tests) data results at several testing periods. Regarding the concrete resistance to freeze and thaw, mass of scaled materials after 28 and 56 cycles are presented in Table VI along with the air distribution data. Note that scaled values at 28 days were published in the following article [26].

Table IV

Fresh properties of SCC mixtures

\begin{tabular}{|l|c|c|c|c|c|c|}
\hline & NAE & NAE & NAE & AE & AE & AE \\
Concrete property & R1 & M1 & S1 & R1 & M1 & S1 \\
\hline Slump flow (mm) & 800 & 775 & 765 & 790 & 790 & 750 \\
\hline V-funnel (seconds) & 5 & 7.13 & 5.28 & 4.91 & 9.48 & 6.55 \\
\hline
\end{tabular}

Table $V$

Compressive strength, splitting tensile strength, water absorption and hardened density of tested SCC mixtures

\begin{tabular}{|l|l|c|c|c|c|c|c|}
\hline & $\begin{array}{c}\text { Testing } \\
\text { time }\end{array}$ & $\begin{array}{c}\text { NAE } \\
\text { R1 }\end{array}$ & $\begin{array}{c}\text { NAE } \\
\text { M1 }\end{array}$ & $\begin{array}{c}\text { NAE } \\
\text { S1 }\end{array}$ & $\begin{array}{c}\text { AE } \\
\text { R1 }\end{array}$ & $\begin{array}{c}\text { AE } \\
\text { M1 }\end{array}$ & $\begin{array}{c}\text { AE } \\
\text { S1 }\end{array}$ \\
\hline & 7 days & 39 & 43 & 44 & 26 & 31 & 34 \\
Compressive strength, MPa & 28 days & 58 & 61 & 59 & 38 & 46 & 43 \\
& 56 days & 65 & 69 & 64 & 40 & 54 & 47 \\
& 400 days & 72 & 81 & 77 & 45 & 57 & 49 \\
Splitting tensile strength, MPa & 400 days & 4.68 & 3.99 & 4.16 & 3.51 & 3.11 & 3.58 \\
Body density, $\mathrm{kg} / \mathrm{m}^{3}$ & 28 days & 2357 & 2336 & 2355 & 2177 & 2198 & 2083 \\
Water absorption by & & & & & & & \\
immersion, V \% & 400 days & 5.59 & 3.50 & 4.54 & 8.43 & 7.45 & 6.96 \\
\hline
\end{tabular}


Table VI

Air void characteristics and mass of scaled materials for tested SCC mixtures

\begin{tabular}{|l|c|c|c|c|c|c|}
\hline \multicolumn{2}{|l|}{ Air void characteristics } & & & \multicolumn{2}{c|}{ Mass of scaled material, $\mathrm{kg} / \mathrm{m}^{2}$} \\
\hline & $A(\%)$ & $\alpha\left(\mathrm{mm}^{-1}\right)$ & $L(\mathrm{~mm})$ & $A_{300}(\%)$ & 28 cycles & 56 cycles \\
NAE -R1 & 5.19 & 17.93 & 0.312 & 1.01 & 0.35 & 0.44 \\
NAE -M1 & 3.47 & 19.39 & 0.346 & 0.53 & 0.21 & 0.29 \\
NAE -S1 & 3.65 & 10.41 & 0.631 & 0.15 & 0.37 & 0.55 \\
AE -R1 & 13.04 & 21.2 & 0.148 & 4.66 & 0.27 & 0.32 \\
AE -M1 & 11.75 & 23.12 & 0.151 & 5.47 & 0.17 & 0.19 \\
AE -S1 & 12.62 & 32.17 & 0.101 & 6.72 & 0.14 & 0.19 \\
\hline
\end{tabular}

\subsection{Compressive and splitting tensile strength}

The compressive strengths were evaluated at the 7, 28, 56 and 400 days whereas the splitting tensile strength at 400 days only. The absolute values are shown in Table $V$. From the results, the impact of air entraining admixture and SCMs can be noticed on the mechanical response of SCC mixtures at different magnitudes (Fig. 2 - Fig. 3).

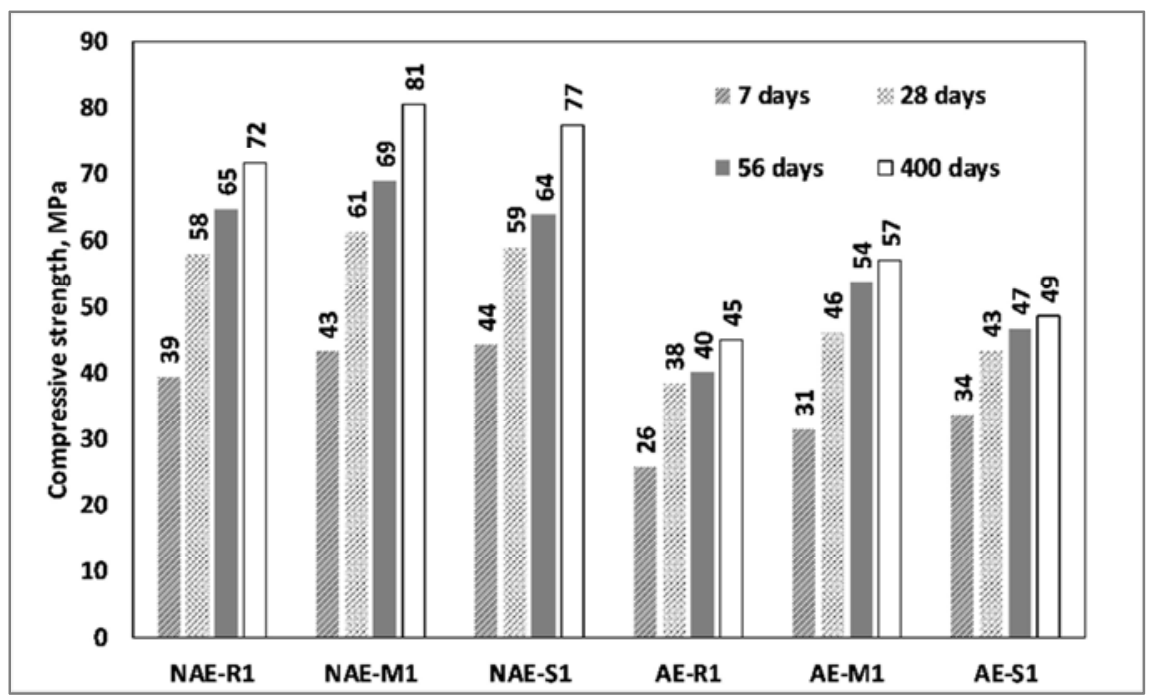

Fig. 2. Compressive strength at 7, 28, 56 and 400 days of SCC mixtures

In both NAE and AE cases, metakaolin mixtures exhibited the maximum values of compressive strength. Fig. 2 illustrates the mean compressive strength of all SCC mixtures separately (average of three individual specimens). At the 28 days of age, metakaolin mixture seemed to be the most effective in compressive strength in comparison with the reference (NAE-R1) and the silica fume (NAE-S1) mixtures, reaching a maximum compressive strength value of $69 \mathrm{MPa}$ (NAE-M1). When air entraining admixture was introduced to the other series, the compressive strength values 
dropped in a range between $32-52 \%$ in accordance with their matching mixture in NAE series.

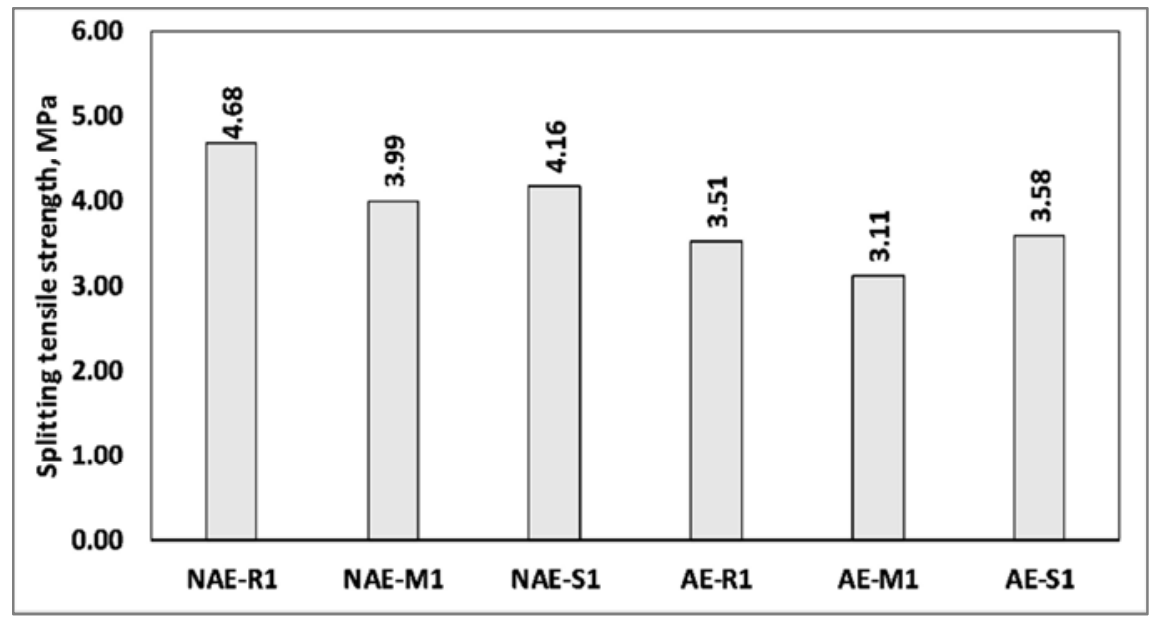

Fig. 3. Splitting tensile strength at 400 days of SCC mixtures

Moreover, metakaolin mixture (AE-M1) showed the highest value of compressive strength of $46 \mathrm{MPa}$ in comparison with the other mixtures in the same AE series. According to Safiuddin et al. [27], by increasing the air content in SCC, the compressive strength decreases. This reduction in compressive strength was about 4 MPa per $1 \%$ increase in air content at fresh state. In this study, the compressive strength dropped $2 \%$ with the increase of $1 \%$ of air content in hardened concrete state referring to EN 480-11 transverse method results.

On the other hand, the splitting tensile strength values did not show a significant difference between mixtures in the same series. However, AE series mixtures showed a decrease ranged between 16 and $33 \%$ in comparison with their matching mixtures NAE series.

\subsection{Density and water absorption}

The mean body density was tested at 28 days of age. Referring to Fig. 4, it can be directly noticed that there is a slight difference between the values of densities in the same series. However, the air entraining admixtures caused a noticeable decrease in the density values ranged between $6 \%$ and $13 \%$ with respect to their matching mixtures (NAE series).

Water absorption by immersion test was carried out at the 400 days of concrete age in order to evaluate the apparent porosity (water content in volume that corresponds to the atmospheric water saturated condition). Absolute mean values of the results are illustrated in Fig. 4. It can be observed that the specimens that contain metakaolin absorbed less water than the specimens with silica fume or without any SCMs. In case of the use of air entraining admixture in AE series, a noticeable increase of apparent 
porosity was noticed, reaching a maximum value of $8.43 \%$ for the reference mixture (AE-R1). This significant increase in AE series ranged between 50\% and $212 \%$ with respect to their matching mixtures in NAE series. The water absorption of high-quality SCC is usually less than 5\% [28]. Thus, NAE series confirms to fall into this category.

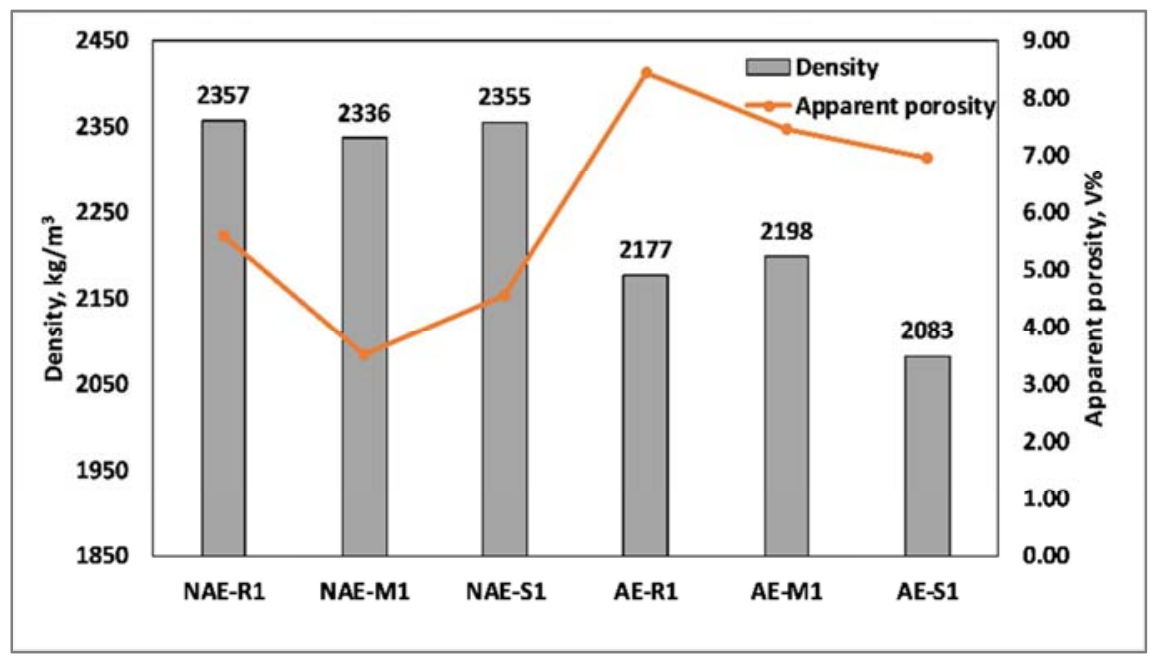

Fig. 4. Hardened density and apparent porosity of SCC mixtures

\subsection{Air void characteristics and frost-salt scaling}

Air void analysis in hardened state of SCC mixtures revealed some major differences between NAE and AE series. The total volume of air in hardened concrete was found to increase drastically with the introduction of the synthetic type air entraining admixture. At a constant dosage $(0.15 \%$ of cement content of air entraining admixture), the air content in the AE series mixtures increased up to 3 times the values in NAE series mixtures. The reason behind this dramatic increase is the high dosage of air entraining admixture and the short mixing time which did not exceed 7 minutes [29]. Also since the targeted classification of slump flow table SF3 requires high level of workability, the HRWRA contributed along with the air entraining admixture with the increase of air voids.

Table VI and Fig. 5 present the frost-scaling resistance and air void characteristics results for SCC mixtures. Scaled material after 28 and 56 cycles could give a clear indication about the durability potential of tested concretes against freezing-thawing cycles. SCC mixtures were tested at the age of 90 days.

The frost resistance of all SCC mixtures was fulfilled since it falls below the commonly assumed acceptable performance (mass of scaled material $\leq 1 \mathrm{~kg} / \mathrm{m}^{2}$ ). However, with the use of air entraining admixture in AE series, the mass of scaled materials significantly dropped in accordance with NAE series. Regarding the SCM effect, metakaolin clearly showed a better response in terms of enhancing the resistance against salt-scaling. The latter was proved by Hassan et al. [30]. Based on EN 480-11 
method, air void distribution in hardened concrete is given in Fig. 6 - Fig. 8 in terms of the range diameters $(0-4000 \mu \mathrm{m})$. When metakaolin or silica fumes are used (NAE-M1 or NAE-S1) a decrease of small voids content could be reached with comparison to reference mixture (NAE-R1). Therefore, for comparative purposes, it can be seen in this case that there is almost no air voids below $300 \mu \mathrm{m}$ for NAE series (Fig. 6 - Fig. 8).

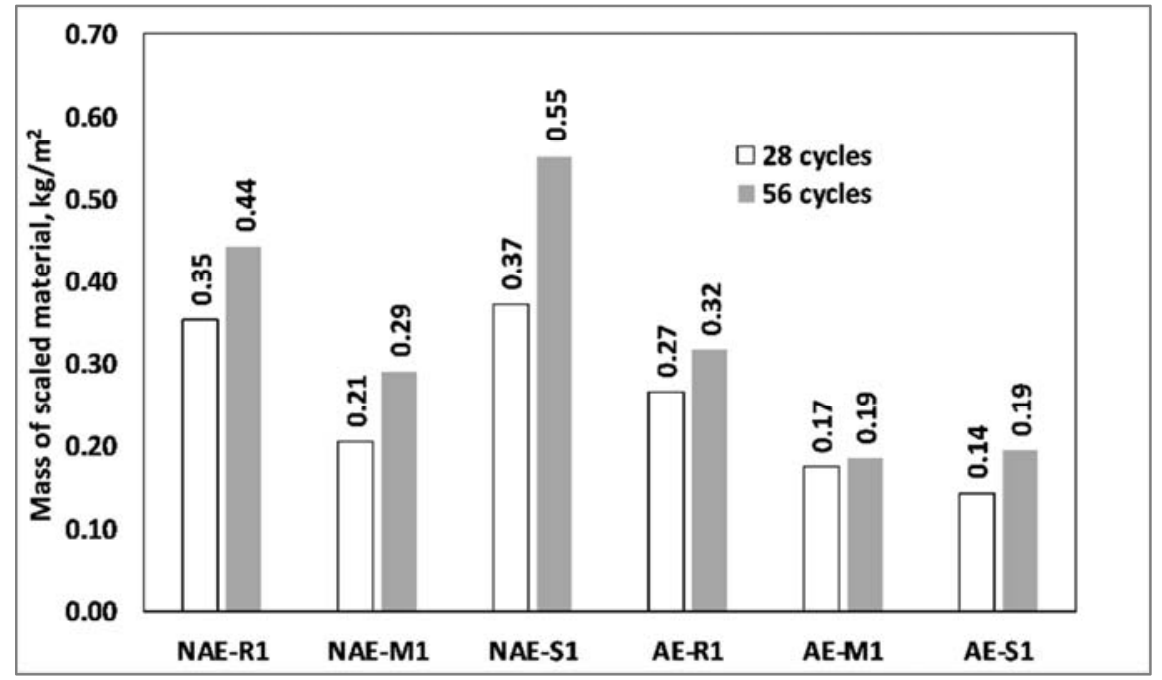

Fig. 5. Hardened density and apparent porosity of SCC mixtures

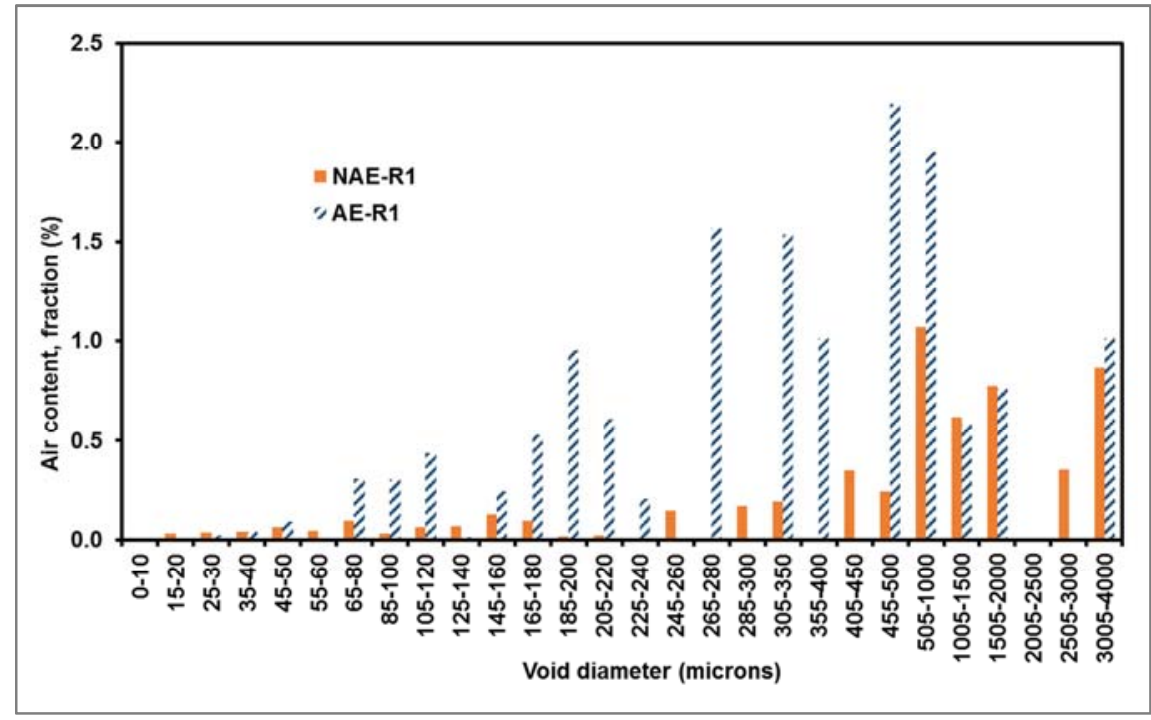

Fig. 6. Air void size distribution in hardened concrete according to EN 480-11 for R1 mixtures 


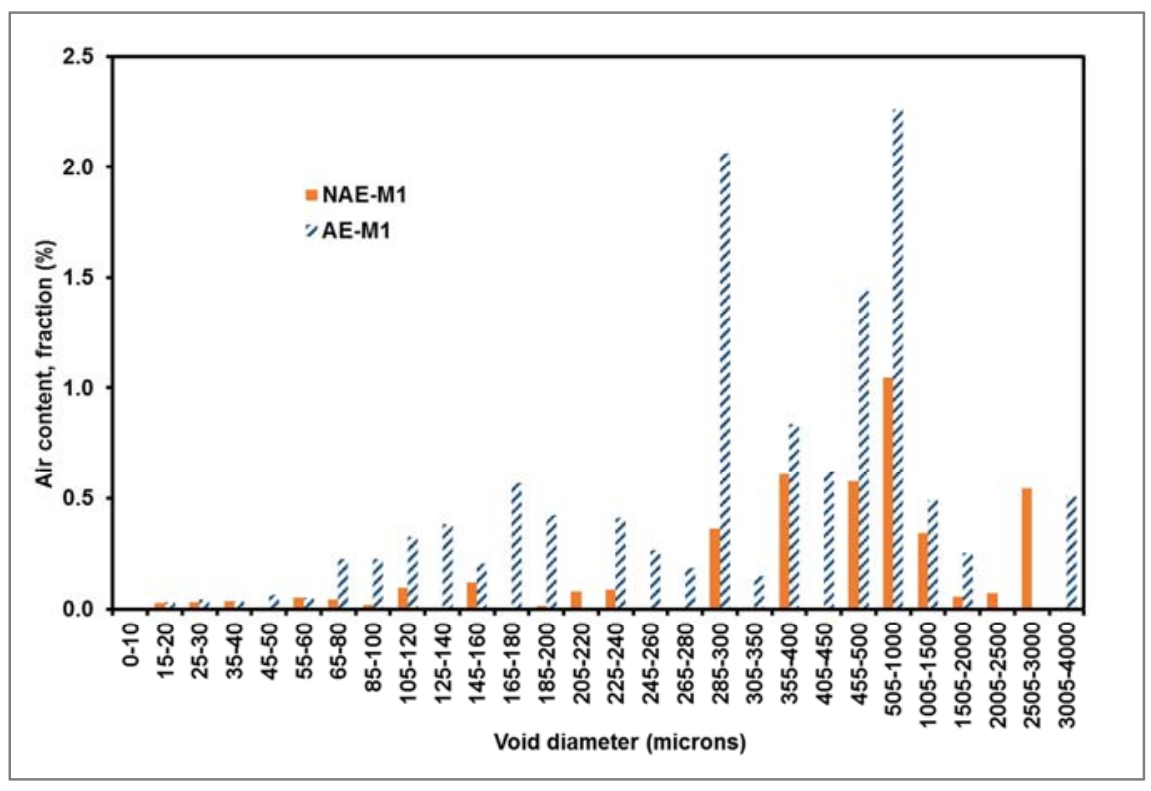

Fig. 7. Air void size distribution in hardened concrete according to

$$
\text { EN 480-11 for M1 mixtures }
$$

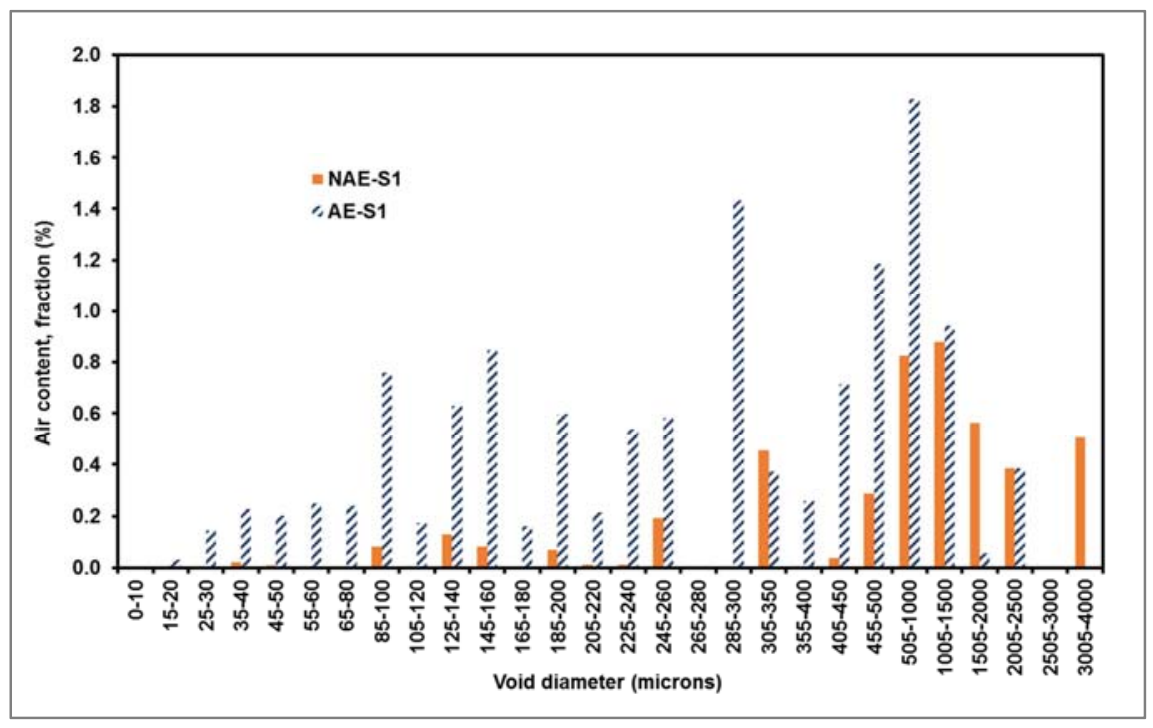

Fig. 8. Air void size distribution in hardened concrete according to EN 480-11 for S1 mixtures 
Obviously air entraining admixture drastically increased the air content at a high level of water-cement ratio. The reason of such effect was the influence of the HRWRA along with the air entraining admixture on the decreasing of the liquid phase in surface tension in the paste microstructure [11].

\section{Conclusions}

Based on the experimental results for various SCC types produced and evaluated in this study, the following conclusions can be drawn:

a. The compressive strength results of SCC were enhanced with SCMs due to the improved microstructure (micro-filling and pozzolanic activity effect), resulting in more hydrated products in presence with the cement binder;

b. Metakaolin mixtures govern the mechanical properties results. A higher value of the compressive strength is reached with metakaolin rather than using silica fume at the same level of addition ( $12.5 \%$ of the cement mass);

c. In hardened concrete, the addition of metakaolin and silica fume had a positive effect on the apparent porosity, providing an enhanced capillary microstructure;

d. In case of non-air entrained mixtures, individual use of metakaolin enhanced the resistance against the frost scaling rather than by silica fume (after 56 cycles);

e. The use of $0.15 \%$ mass of air entraining admixture per unit of cement resulted in high values of air content;

f. The increased air content directly affected the mechanical properties; Compressive strength by a significant drop since the air entraining admixture supplied air voids, achieving higher total void content.

\section{Acknowledgements}

Authors acknowledge the support of 'LAFARGE' and 'SIKA' for supplying the materials. Also the experimental air void tests performed in collaboration with 'Debrecen University' were fulfilled with Mr. József Kovács.

\section{References}

[1] Okamura H., Ouchi M. Self-compacting high performance concrete, Prog. Struct. Eng. Mater, Vol. 1, No. 4, 1998, pp. 378-383.

[2] Okamura H., Ouchi M. Self-compacting concrete, J. Adv. Concr. Technol, Vol. 1, No. 1, 2003, pp. 5-15.

[3] Khayat K. H., Assaad J. J. Air-void stability in self-consolidating concrete, ACI Mater. J, Vol. 99, No. 4, 2002, pp. 408-416.

[4] Borosnyói A. Long term durability performance and mechanical properties of high performance concretes with combined use of supplementary cementing materials, Constr. Build. Mater, Vol. 112, 2016, pp. 307-324. 
[5] Uysal M., Yilmaz K., Ipek M. The effect of mineral admixtures on mechanical properties, chloride ion permeability and impermeability of self-compacting concrete, Constr. Build. Mater, Vol. 27, No. 1, 2012, pp. 263-270.

[6] Puentes J., Barluenga G., Palomar I. Effect of silica-based nano and micro additions on SCC at early age and on hardened porosity and permeability, Constr. Build. Mater, Vol. 81, 2015, pp. 154-161.

[7] Elyamany H. E., Elmoaty A., Mohamed B. Effect of filler types on physical, mechanical and microstructure of self-compacting concrete and flow-able concrete, Alexandria Engineering Journal, Vol. 53, No. 2, 2014, pp. 295-307.

[8] Junak J., Stevulova N., Ondova M. Concrete samples prepared with different types of waste, Pollack Periodica, Vol. 9, Supplement 1, 2014, pp. 95-104.

[9] Ondova M., Stevulova N., Palascakova L., Estokova A. The study of concrete properties prepared with a proportion of fly ash, Pollack Periodica, Vol. 9, Supplement 1, 2014, pp. $105-115$.

[10] ACI 201.2R-08 Guide to durable concrete, ACI, 2008.

[11] Szwabowski J., Łaźniewska-Piekarczyk B. The increase of air content in SCC mixes under the influence of carboxylate superplasticizer, Cement, Wapno, Beton, Vol 4. 2008, pp. 205-215.

[12] Du L., Folliard K. J. Mechanisms of air entrainment in concrete, Cem. Concr. Res, Vol. 35, 2005, pp. 1463-1471.

[13] Struble L. J., Jiang Q. Effect of air entrainment on rheology, ACI Materials Journal, Vol. 101, No. 6, 2004, pp. 448-456.

[14] Łaźniewska-Piekarczyk B. The frost resistance versus air voids parameters of high performance self-compacting concrete modified by non-air-entrained admixtures, Constr. Build. Mater, Vol. 48, 2013, pp. 1209-1220.

[15] BS-EN480-11:2005, Admixtures for concrete, mortar and grout, Test methods, Part 11, Determination of air void characteristics in hardened concrete, Br. Stand, 2005.

[16] BS-EN197-1:2011, Cement. Part 1, Composition, specifications and conformity criteria for common cements, $B r$. Stand, 2011.

[17] MSZ EN 12620:2002+A1:2008, Aggregates for concrete, Magyar Szabványügyi Testület, 2008.

[18] EFNARC, The European guidelines for self-compacting concrete, Eur. Guidel. SelfCompact. Concr, 2005.

[19] BS EN 934-2:2009+A1:2012, Admixtures for concrete, mortar and grout, Part 2, Concrete admixtures - Definitions, requirements, conformity, marking and labelling, Br. Stand, 2012.

[20] BS-EN12350-8:2010, Testing fresh concrete, Part 8, Self-compacting concrete - Slumpflow test, Br. Stand, 2010.

[21] BS-EN12350-9:2010, Testing fresh concrete, Part 9, Self-compacting concrete - V-funnel test, Br. Stand, 2010.

[22] BS-EN12390-3:2009, Testing hardened concrete, Part 3, Compressive strength of test specimens, Br. Stand, 2009.

[23] BS-EN12390-6:2009, Testing hardened concrete, Part 6, Tensile splitting strength of test specimens, Br. Stand, 2009.

[24] BS-EN12390-7:2009, Testing hardened concrete, Part 7, Density of hardened concrete, $B r$. Stand, 2009.

[25] DD CEN/TS 12390-9:2006 Testing hardened concrete, Part 9, Freeze-thaw resistance scaling, Br. Stand, 2006.

[26] El Mir A., Nehme S. Comparison of durability performance of conventional and airentrained self-compacting concrete modified by metakaolin and silica fume, SCC $2016-8^{\text {th }}$ International RILEM Symposium on Self-Compacting Concrete, Washington DC, USA, 1518 May 2016, pp. 387-398. 
[27] Safiuddin M. D., West J. S., Soudki K. A. Hardened properties of self-consolidating high performance concrete including rice husk ash, Cem. Concr. Compos, Vol. 32, 2010, pp. 708-717.

[28] Kosmatka S. H., Wilson M. L. Design and control of concrete mixtures, The guide to applications, methods, and materials, EB001, 15th edition, Portland Cement Association, Skokie, Illinois, USA, 2011.

[29] Ouchi M., Attachaiyawuth A. Development of air-enhanced self-compacting concrete, 8th International RILEM Symposium on Self-Compacting Concrete, SCC 2016, Washington D.C., U.S.A., 15-18 May 2016, pp. 15-24.

[30] Hassan A. A. A., Lachemi M., Hossain K. M. A. Effect of metakaolin and silica fume on the durability of self-consolidating concrete, Cem. Concr. Compos, Vol. 34, 2012, pp. 801-807. 